\title{
Repression of human heat shock factor 1 activity at control temperature by phosphorylation
}

\author{
Ursula Knauf, ${ }^{1,3,4}$ Elizabeth M. Newton,, ${ }^{1,3,4}$ John Kyriakis, ${ }^{2}$ and Robert E. Kingston ${ }^{1,3,5}$ \\ ${ }^{1}$ Department of Molecular Biology and ${ }^{2}$ Diabetes Unit, Massachusetts General Hospital, Boston, Massachusetts 02114 USA; \\ ${ }^{3}$ Department of Genetics, Harvard Medical School, Massachusetts USA
}

\begin{abstract}
Human heat shock transcription factor 1 (HSF1) is responsible for stress-induced transcription of heat shock protein genes. The activity of the HSF1 transcriptional activation domains is modulated by a separate regulatory domain, which confers repression at control temperature and heat inducibility. We show here that two specific proline-directed serine motifs are important for function of the regulatory domain: Mutation of these serines to alanine derepresses HSF1 activity at control temperature, and mutation to glutamic acid, mimicking a phosphorylated serine, results in normal repression at control temperature and normal heat shock inducibility. Tryptic mapping shows that these serines are the major phosphorylation sites of HSF1 at control temperature in vivo. Stimulation of the Raf/ERK pathway in vivo results in an increased level of phosphorylation of these major sites and the regulatory domain is an excellent substrate in vitro for the mitogen-activated MAPK/ERK. We conclude that phosphorylation of the regulatory domain of HSF1 decreases the activity of HSF1 at control temperature, and propose a mechanism for modification of HSF1 activity by growth control signals.
\end{abstract}

[Key Words: heat shock factor; transcription factor; HSF1; Raf/ERK; phosphorylation]

Received April 12, 1996; revised version accepted August 29, 1996.

Transcription of mammalian heat shock protein genes is regulated by a family of heat shock transcription factors (for review, see Morimoto et al. 1992; Lis and Wu 1993). Heat shock factor 1 (HSF1) plays the primary role in regulating these genes in response to chemical and thermal stress (Sistonen et al. 1992). HSF1 is constitutively found in an inactive form in mammalian cells, and is activated by two processes. The ability of HSFl to bind DNA is regulated by a structural transition from an inactive monomer to an active trimer (Sorger and Nelson 1989; Westwood and Wu 1993; Larson et al. 1995|, and the ability of the transcriptional activation domains to stimulate transcription is regulated by a separate regulatory domain (Green et al. 1995; Shi et al. 1995; Zuo et al. 1995). This regulatory domain, located in the central portion of HSF1, can confer heat-induced transcriptional regulation on an activator that contains a heterologous DNA-binding domain and a heterologous transcriptional activation domain (Newton et al. 1996). This implies that the regulatory domain is sufficient to sense heat stress, and that this domain is a prime candidate to receive signals that modulate HSF1 activity.

Phosphorylation of HSF1 might be one mechanism by which HSF1 function is modulated. Heat shock factors

${ }^{4}$ These authors contributed equally to this work.

${ }^{5}$ Corresponding author. from yeast to humans have similar structures, and these factors are phosphorylated at serine and threonine residues at control temperature and are hyperphosphorylated following heat shock (Sorger 1990; Cotto et al. 1996). It does not appear that heat-induced hyperphosphorylation of the transcriptional activation domains is necessary for activation of human HSF1 following heat shock, as fusion proteins deleted for heat-induced phosphorylation sites remain heat-inducible (Newton et al. 1996). However, mutational analyses of HSF from the budding yeast Kluveromyces lactis suggest that hyperphosphorylation of serines might be involved in deactivation of HSF following heat shock (Hoj and Jakobsen 1994). The role of constitutive phosphorylation of HSFs has not yet been addressed.

Phosphorylation of transcription factors can occur through a number of different pathways in the cell, three of which are MAP (mitogen-activated protein) kinase pathways: the Raf/ERK (extracellular-signal-regulated kinase) pathway, the MEKK/SAPK(JNK) (stress a activated protein kinase/Jun $\mathrm{N}$-terminal kinasel pathway and the p38(RK)|HOG1) (reactivating kinase/high osmolarity glycerol response 1) pathway (for review, see Cano and Mahadevan 1995; Karin and Hunter 1995). These pathways result in the activation of kinases that phosphorylate Ser/Thr-Pro motifs and that are thus referred to as proline-directed kinases. The Raf/ERK pathway results 
in the stimulation of the most thoroughly studied MAP kinases, ERK1 and ERK2, through activation of receptor tyrosine kinases in response to growth factors. This pathway uses Ras/Raf signaling to activate MEK1/ MEK2 (MAP kinase kinase), which phosphorylates ERK1 and ERK2, stimulating their activity. The SAPKs are a family of MAP kinases distinct from the ERKs that are activated by cellular stress as opposed to growth factors (Derijard et al. 1994; Kyriakis et al. 1994). The upstream regulation of this pathway is less well understood than the ERK pathway; however, SAPK is believed to be activated by a MEK equivalent called SEK1(JNKK1)(MKK4) (Sanchez et al. 1994; Derijard et al. 1995; Lin et al. 1995), which appears itself to be regulated by MEKK (MAP kinase kinase kinase) (Lange-Carter et al. 1993; Yan et al. 1994). p38 is also a stress-activated kinase (Han et al. 1994; Rouse et al. 1994), which appears to be activated by other MEK family members, MKK3 and MKK6 (Derijard et al. 1995; Raingeaud et al. 1996) and MKK4. Both the ERK pathway and the SAPK pathway can be activated by a mechanism involving Ras, however Raf- 1 contributes only to ERK activation but not SAPK activation (Minden et al. 1994).

In this study, we have examined phosphorylation of the regulatory domain of HSFl. Inspection of the sequence of this domain revealed six proline-directed serine motifs that are conserved between human and chicken HSF1. This observation raised the possibility that these serines might receive signals from MAP kinase-related pathways. We have found that the regulatory domain can be phosphorylated by ERK1/ERK2 in vitro and in a Raf-1-dependent manner in vivo. Mutational analysis of the proline-directed serine motifs in the regulatory domain indicates that phosphorylation of these serines causes decreased function of the transcriptional activation domains at control temperature, whereas the nonphosphorylated state increases function of the transcriptional activation domains. Thus, phosphorylation appears to down-regulate HSFl via some of the same kinases that up-regulate transcription factors involved in cell growth decisions.

\section{Results \\ Proline-directed serine motifs in the regulatory domain are necessary for full repression of activation at control temperature}

Transcriptional activation by HSF1 is repressed at control temperature and heat shock inducible. Transcriptional activation is controlled by the regulatory domain, amino acids $221-310$, that contains six conserved proline-directed serine motifs. To study a possible role for these serines in heat-induced regulation, we mutated a fusion protein containing the DNA-binding and dimerization domain of GAL4, the regulatory domain of HSF1 (amino acids 201-370) and the proximal activation domain of HSFl, AD1 (amino acids 401-420), as this construct was shown previously to be a potent, heat-inducible activator (Newton et al. 1996). Transcriptional acti- vation was evaluated using S1 analysis following cotransfection of HeLa cells with a GAL4 expression plasmid and a CAT reporter containing five GAL4 sites. An internal reference plasmid was included that contains the basal $h s p 70$ promoter (lacking HSEs) with a deletion in the $5^{\prime}$ untranslated region that results in a shorter product than the wild-type gene following S1 analysis.

Point mutation of the six proline-directed serines to alanine caused significant derepression of transcriptional activation at control temperature (Fig. 1A, lane 3). Basal activation was increased approximately fourfold. However, this construct was not completely derepressed, as heat shock induced activation a further three- to fourfold. We also mutated these serines into glutamic acid to mimic the negative charge of a phosphorylated serine and found that this mutation was fully repressed at control temperature and heat shock-inducible, similar to wild type (Fig. 1A, lanes 5,6 ). We then asked if all six serines were necessary for this effect and found that $\mathrm{mu}$ tation of only serines 303 and 307 to alanine was sufficient to cause the derepressed phenotype (Fig. 1A, lanes 7,81 , and once again mutation to glutamic acid appeared wild-type (lanes 9,10). These point mutations have no effect on either the stability or the binding of the GAL4 fusion proteins as shown by gel shift analysis using nuclear extracts made from transfected cells and a probe containing a single GAL4 binding site (Fig. 1B). The GAL4 specific bands are supershifted using a GAL4 specific antibody to distinguish GAL4 activity from the often obscuring nonspecific bands present in untransfected cells (Fig. 1B, lanes 21,22). Addition of the antibody also appears to stabilize the interaction between the DNA binding domain and the DNA, causing an increase in amount of complex in the supershift.

To determine whether the serine residues that are important for the function of the regulatory domain are phosphorylated in vivo, transfected 293T cells were pulse-labeled with ${ }^{32} \mathrm{P}_{\mathrm{i}}$ for $1 \mathrm{hr}$ followed by immunoprecipitation with a GAL4- or HSF1-specific antiserum. $293 \mathrm{~T}$ cells, which gave similar transactivation results for the point mutants as HeLa cells (data not shown), were used for labeling experiments because of their high transfection efficiency. Endogenous HSF1 from mock-transfected cells is partly phosphorylated at $37^{\circ} \mathrm{C}$ and hyperphosphorylated following heat shock (Fig. 1C, lanes 9,10; Sarge et al. 1993). In contrast to this, the GAL4-HSF1 fusion containing the wild-type regulatory domain of HSF1 is phosphorylated at control temperature and shows no increase in phosphorylation after heat treatment (lanes 1,2). Substitution of serines 303 and 307 with alanine leads to decreased phosphorylation at both temperatures and an increased electrophoretic mobility of the GAL4 fusion protein, which is consistent with previously observed effects of dephosphorylation on HSF mobility (lanes 3,4). Mutation of all six proline-directed serines to alanine decreased phosphorylation and increased the mobility of the GAL4-fusion proteins (lanes $5,6)$, whereas mutation of all serines to glutamic acid also decreased phosphorylation, but decreased mobility 
Knauf et al.

Figure 1. Proline-directed serine motifs 303 and 307 in the regulatory domain of HSFl are necessary for transcriptional repression at control temperature. (A) S1 analysis of the effects of serine point mutations on activity of GAL4-HSFl fusion proteins. Signals were quantified by a PhosphorImager, and transactivation was calculated by dividing the signal band by the internal reference (Int. Ref.) band. Heat shock (4-hr heat shock at $43^{\circ} \mathrm{C}$ ) was performed as indicated. Fold heat induction is the level at $43^{\circ} \mathrm{C}$ divided by the level at $37^{\circ} \mathrm{C}$. (WT) Wild-type; (AD1) activation domain 1. (B) Gel shift analysis comparing expression of mutant GAL4 fusion proteins with wild-type expression in cells transfected in parallel with those for $A$. The GAL4 DNA-binding domain-containing species (indicated by arrows) were supershifted with specific antisera. Lane 23 is probe alone. $(C)$ In vivo phosphorylation of GAL4-HSF1 constructs. GAL4 fusion proteins were immunopurified from ${ }^{32} \mathrm{P}_{\mathrm{i}}$ labeled 293T cells transfected with GAL4 RD-ADI constructs harboring the indicated point mutations within the regulatory domain (lanes 1-8). As a control phosphorylation of endogenous HSF1 from mock-transfected cells was analyzed (lanes 9,10). ${ }^{32} \mathrm{P}_{\mathrm{i}}$-labeling was performed for $1 \mathrm{hr}$ at either $37^{\circ} \mathrm{C}(-)$ or $43^{\circ} \mathrm{C}(+)$. (D) Western blot analysis of parallel sets of transfected $293 \mathrm{~T}$ cells as shown in $C$ using a GAL4-specific antiserum.

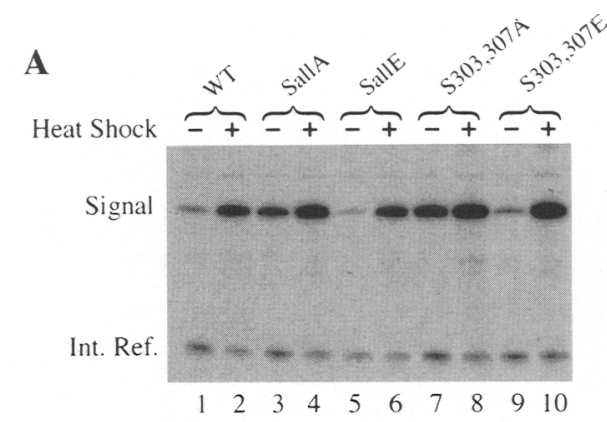

\begin{tabular}{|c|c|c|c|c|c|c|c|c|}
\hline & & & & & & Trans & vation & \\
\hline & GAL4 & $2+$ & $\begin{array}{c}\text { gulatory } \\
275279\end{array}$ & $\begin{array}{l}y \text { domain } \\
925303307\end{array}$ & $\begin{array}{c}\text { AD1 } \\
401 \quad 420\end{array}$ & $37^{\circ} \mathrm{C}$ & $43^{\circ} \mathrm{C}$ & Induction \\
\hline WT & & $\mathbf{S}$ & S S & S S S & 2 & 1.0 & $10.2+1-1.3$ & 10.2 \\
\hline & & $\downarrow$ & $\downarrow \downarrow$ & $\downarrow \downarrow \downarrow$ & 370 & & & \\
\hline SallA & & A & A A & $\mathbf{A} \mathbf{A} \mathbf{A}$ & & $3.7+0.3$ & $15.5+i .2 .4$ & 4.2 \\
\hline Salle & & E & $\mathrm{E} \mathbf{E}$ & E E E & & $1.1+-0.1$ & $9.1+1-0.9$ & 8.3 \\
\hline 303 & & & & $\mathbf{A} \mathrm{A}$ & & $5.1+.0 .4$ & $14.5+<-1.9$ & 2.8 \\
\hline 303, & & & & E E & & $1.2+-0.1$ & $9.4+-0.2$ & 7.8 \\
\hline
\end{tabular}
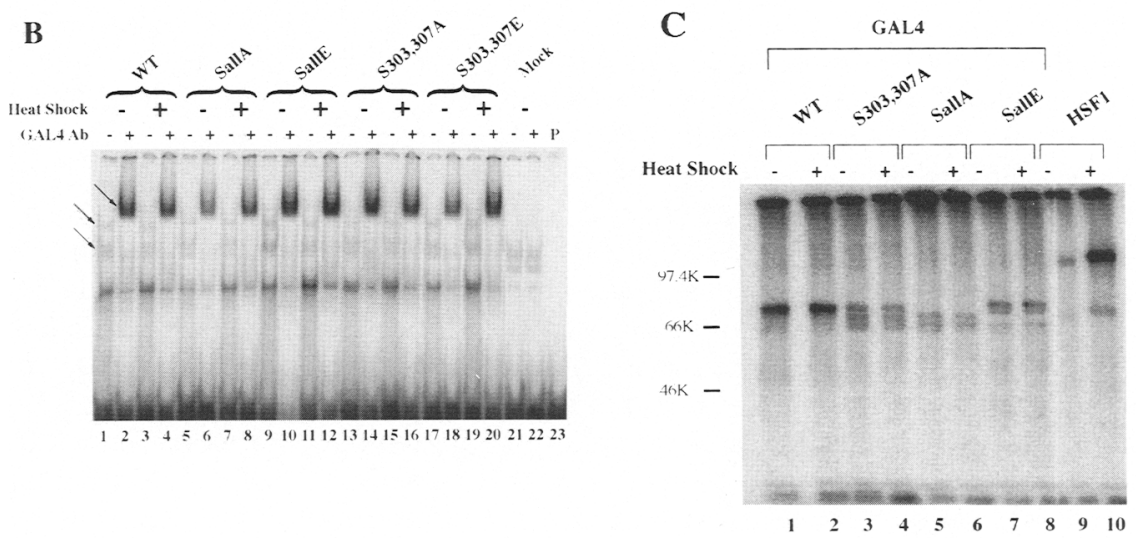

D

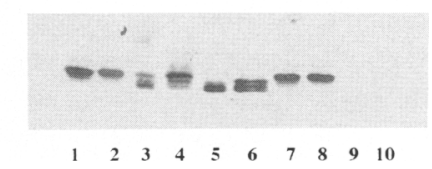

(lanes 7,8). The expression levels of the different GAL4 constructs are equivalent, as shown by Western analysis (Fig. 1D). Both mutant constructs that contained serine to alanine mutations displayed decreased mobility following heat shock (Fig. 1D, lanes 3-6), implying mechanisms other than phosphorylation of these serines contributes to this characteristic mobility shift.

The experiments of Figure 1 suggest that the prolinedirected serine motifs in the regulatory domain are phosphorylated at control temperatures, and that this phosphorylation is important for the ability of the regulatory domain to repress transcriptional activation domain activity at control temperatures. These mutations do not significantly affect induction at heat shock temperatures, suggesting that the phosphorylation state of the regulatory domain is not important following severe stress and that dephosphorylation is not required for heat induction.

\section{Mitogen-activated ERK is able to phosphorylate the regulatory domain of HSF1 in vitro}

Because the regulatory domain of HSFl is phosphorylated at proline-directed serine motifs, we tested the ability of three different MAP kinase family members (ERK, SAPK, and p38) to phosphorylate this domain in vitro. We first tested ERK kinase, as the in vivo labeling data indicated that the regulatory domain was phosphorylated during nonstress conditions. 293T cells expressing a HA-epitope tagged version of ERK1 were serum-deprived overnight and induced with PMA to stimulate the ERK/MAPK pathway. ERK1 was then immunoprecipi- 
tated using 12CA5 mAb. Phosphorylation reactions were performed in vitro using recombinant GST-RD proteins containing either a wild-type or mutant regulatory domain. PMA treatment of the cells led to the activation of ERK, as demonstrated using the myelin basic protein (MBP) (Fig. 2A, lanes 1,2). The wild-type regulatory domain is an excellent substrate for ERK leading to phosphate incorporation of $7400 \mathrm{cpm} / 100$ nmole compared with $2000 \mathrm{cpm} / 100$ nmole when MBP is the substrate. Mutation of serine 303 and 307 partially decreased the level of phosphorylation by ERK to $4900 \mathrm{cpm} / 100 \mathrm{nmole}$ (lanes 5,6$)$. When all six serines are replaced by alanine, PMA-dependent phosphorylation is abolished (lanes 7,8).

We next tested the ability of the MAP kinase relatives SAPK and p38 to phosphorylate the regulatory domain. 293T cells were stimulated with anisomycin and endogenous SAPK or p38 were immunoprecipitated. Anisomy-

$\mathbf{A}$

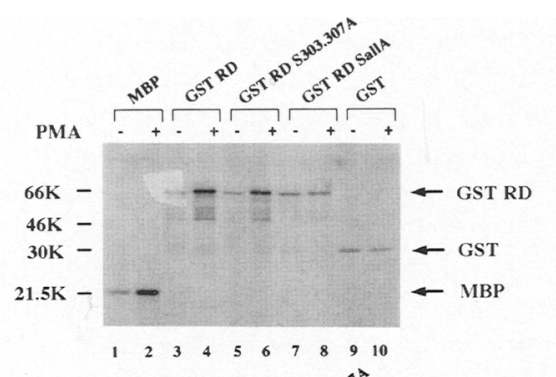

ERK

B

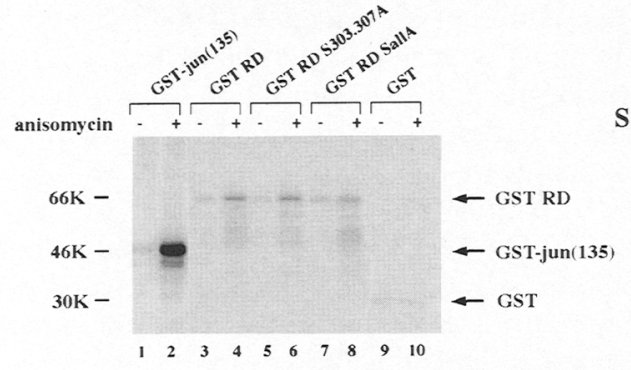

C

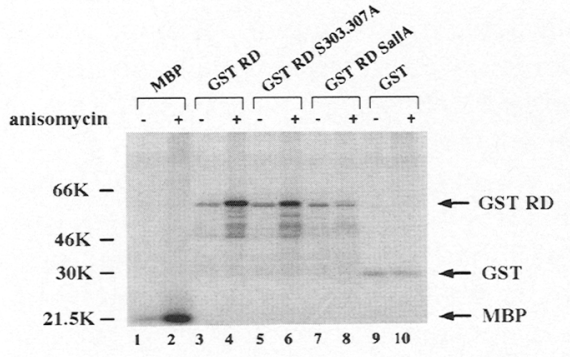

p38

D

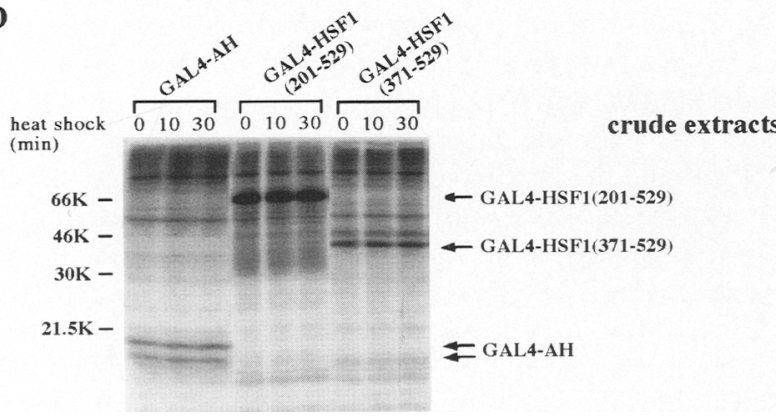

cin is a very potent inducer of SAPK (Kyriakis et al. 1994) and a 19-fold induction of SAPK activity was observed using GST-c Jun(1-135) as a control substrate (Fig. 2B, lane 1,21 . The wild-type regulatory domain is weakly phosphorylated by induced, immunoprecipitated SAPK (lanes 3,4). This weak anisomycin-dependent phosphorylation is not affected by mutation of serine 303 and 307 or by mutation of all six serines and therefore probably reflects phosphorylation at other sites. Surprisingly, immunoprecipitated $\mathrm{p} 38$ phosphorylated the regulatory domain under these conditions to a similar level as ERK1 leading to phosphate incorporation of $45,000 \mathrm{cpm} / 100$ nmole GST-RD (Fig. 2C, lanes 3,4) compared with $38,000 \mathrm{cpm} / 100$ nmole of the S303/307A mutant (lanes $5,6)$ and $15000 \mathrm{cpm} / 100 \mathrm{nmole} \mathrm{MBP}$ as control substrate (lanes 1,2). When the SallA mutant of the regulatory domain is used as substrate, p38-dependent phosphoryla-

Figure 2. In vitro phosphorylation of the regulatory domain by different MAPK family members. (A) ERK immunocomplex kinase assay. 293T cells transfected with pcDNA HA-ERKl (Price et al. 1992) were serum-deprived overnight and stimulated with $200 \mathrm{nM}$ PMA for $20 \mathrm{~min}$. HA-ERK1 was immunoprecipitated and in vitro kinase assays were conducted using 2 $\mu \mathrm{g}$ of myelin basic protein (MBP, lanes 1,2), recombinant GST$\mathrm{RD}$ proteins harboring the indicated point mutations (lanes 3-8), or GST (lanes 9,10) as substrates. Phosphorylation was quantified by PhosphoImager analysis. $(B)$ SAPK and $(C)$ p38 immunocomplex kinase assay. Endogenous SAPK or p38 was immunopurified from $293 \mathrm{~T}$ cells stimulated with $50 \mu \mathrm{g} / \mathrm{ml}$ anisomycin for $40 \mathrm{~min}$. In vitro kinase assays were performed as indicated in $A$ using a GST fusion protein containing the aminoterminal 135 amino acids of c-Jun as a control substrate for SAPK $(B$, lanes 1,2$)$, and MBP as a control substrate for p38 $(C$, lanes 1,2$)$. $(D)$ Phosphorylation by crude extracts from control temperature and heat shocked cells. Hela cells were heatshocked at $43^{\circ} \mathrm{C}$ for the times indicated. Kinase assays were performed as in $A$, except using GAL4-HSFl fusion proteins both with (amino acids 201-529) and without (amino acids 371529) the regulatory domain and GAL4-AH (amphipathic helix) as a control. One microgram of each protein was used and phosphate incorporation was $800 \mathrm{cpm}$ in lanes $1-3,6000 \mathrm{cpm}$ in lanes 4-6, and $1500 \mathrm{cpm}$ in lanes 7-9. The background of phosphorylated cellular proteins is attributable to the use of crude extracts. 
tion is abolished (lanes 7,8$)$. We conclude that the regulatory domain is not a good substrate for SAPK, but is a good substrate for ERK and p38.

The result that $\mathrm{p} 38$ could phosphorylate the regulatory domain was not expected as there is no increase in phosphorylation level in vivo of the regulatory domain upon heat shock (Fig. 1C), which would induce the activity of p38. Therefore, we tested whether extracts from heatshocked cells are capable of increased phosphorylation of the regulatory domain in vitro. There is no increase in the phosphorylation level of the regulatory domain in kinase reactions using extracts from HeLa cells heatshocked for 10 or $30 \mathrm{~min}$ in comparison to extracts from control temperature cells (Fig. 2D). Similar results were obtained using extracts from 293T cells /data not shown). These are conditions that strongly induce the activity of p38 (Rouse et al. 1994), and thus the lack of induced phosphorylation indicates that p38 is likely not the predominant regulatory domain kinase in HeLa or 293T cells. Taken together, these results prompted us to further investigate the phosphorylation by ERK1/ERK2, which remained a candidate to be the predominant regulatory domain kinase.

To confirm that specifically serines 303 and 307 were phosphorylated by ERK, we performed tryptic mapping of the regulatory domain phosphorylated in vitro with purified ERK1/ERK2. Tryptic digest of amino acids 201370 of HSF1 should produce four fragments that contain proline-directed serine motifs; Ser-303 and Ser-307 are on the same tryptic fragment (Fig. 3A). Analysis of a GST fusion containing the wild-type regulatory domain pro-

$\mathbf{A}$

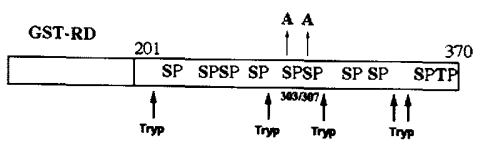

B

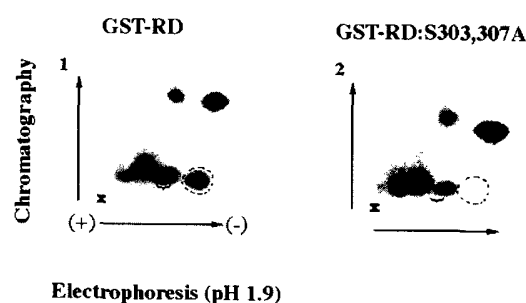

Figure 3. Phosphopeptide map of HSF1 regulatory domain phosphorylated in vitro by ERK1/ERK2. (A) Schematic of GST$\mathrm{RD}$ fusion protein indicating position of trypsin cleavage sites relative to serine 303 and serine 307. (GST) Glutathione $S$-transferase; (RD) regulatory domain. (B) Tryptic phosphopeptide analysis of in vitro phosphorylated GST-RD. Five micrograms of recombinant GST-RD containing the wild-type regulatory domain (1) or the S303,307A double point mutation (2) were phosphorylated in vitro using purified ERK1/2 and 2-D phosphopeptide analysis was performed. The two phosphopeptides absent in the double point mutant are indicated by a bracket and a dotted circle. duced a pattern with seven spots (Fig. 3B, panel 1), two of which are missing when Ser-303 and Ser-307 are mutated to alanine (Fig. 3B, panel 2; marked with bracket and dotted circle). These two spots are either a result of the monophosphorylated peptide and the diphosphorylated peptide, or a result of incomplete digestion at lysine 298 attributable to inhibition by glutamate 299 (Boyle et al. 1991). We conclude that either Ser-303 or Ser-307, or both are phosphorylated by ERK1/ERK2 in vitro.

\section{Stimulation of the Raf/ERK pathway increases phosphorylation of Ser303/307 in vivo}

Phosphorylation of the regulatory domain in the above experiments was measured using fusion proteins. In intact HSF 1, the factor undergoes a transition from monomer to trimer following heat shock, and this apparently requires a conformational change in the protein (Westwood and Wu 1993; Larson et al. 1995) that might affect accessibility of the regulatory domain at control or heat shock temperatures. To test whether the regulatory domain of intact HSF1 is phosphorylated by the Raf/ERK signal transduction pathway in vivo, serine mutations were introduced into an epitope-tagged full-length HSF1 vector and wild-type or mutant forms of this vector were cotransfected with an expression vector encoding a constitutively active Raf. Cells were labeled metabolically and HSF was immunoprecipitated using an anti-FLAG antibody. Expression of Raf increased HSF phosphorylation 4.8-fold under control (Fig. 4A; lanes 1,2) or 5.1-fold under heat shock conditions (lanes 3,4). Mutation of the six proline-directed serines to alanine led to a significant decrease in Raf-dependent phosphorylation to 2.4-fold and 1.6-fold at control and heat shock temperature, respectively (lanes 5-8). Both HSFl constructs show higher phosphorylation following heat shock compared with control temperature; this is consistent with the observation of heat-inducible phosphorylation of endogenous HSF1, which is believed to occur at positions outside the regulatory domain. Expression levels of the FLAG epitope-tagged HSFl constructs were constant, as shown by Western blot analysis (Fig. 4B).

To determine whether serines 303 and 307 are phosphorylated in vivo, tryptic digests were performed on endogenous HSF that had been immunoprecipitated following metabolic labeling of HeLa cells. The tryptic map produces one major spot at control temperature (Fig. 4C, indicated by bracket). Mixing experiments with wildtype and mutant regulatory domain phosphorylated in vitro (samples from Fig. 3) showed that this major spot comigrated with the fragment containing Ser303/307 (data not shown). In addition, cotransfection of tagged HSFl and constitutive Raf led to an increased phosphorylation of this spot (Fig. 4D, cf. panels 1 and 2). This spot disappears when Ser303 and Ser307 are mutated to alanine (Fig. 4D, panels 3,4). We conclude that the regulatory domain of intact HSF1 is phosphorylated at proline-directed serine motifs $303 / 307$, and that this phosphorylation can be modulated by Raf coexpression. 


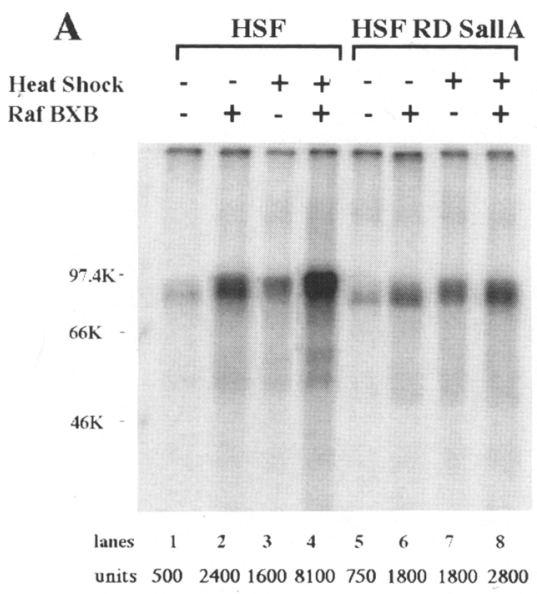

B

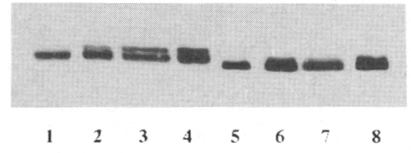

C

endogenous HSF1-control temp.

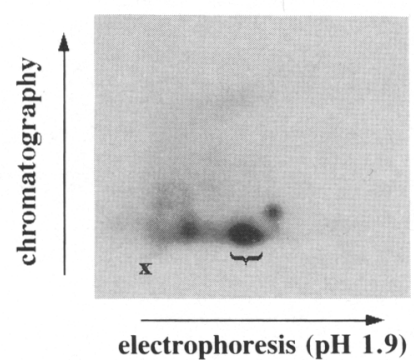

D
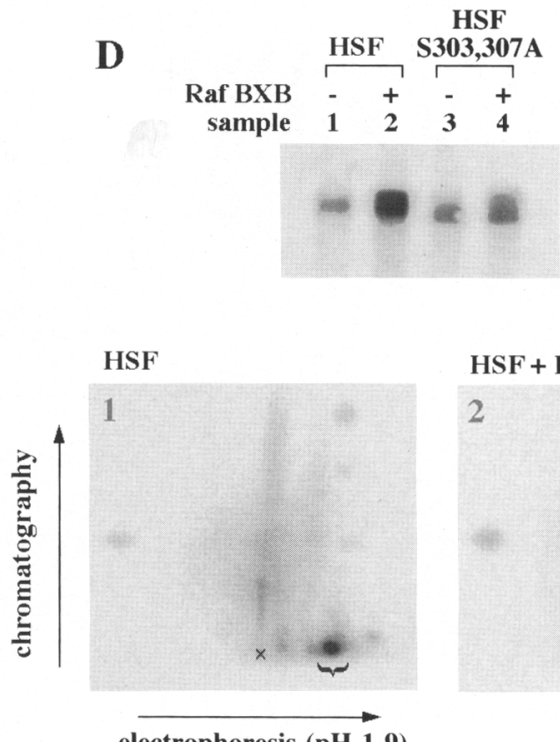

HSF + Raf BXB

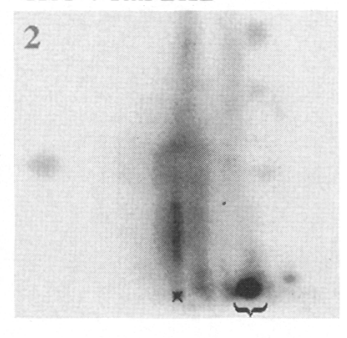

electrophoresis $(\mathrm{pH} 1.9)$

HSF S303,307A

3

HSF S303,307A + Raf BXB

4
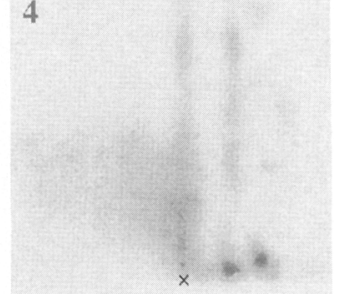

Figure 4. Proline-directed serine motifs 303 and 307 are targets for Raf-dependent phosphorylation in HSFl in vivo. (A) In vivo phosphorylation of transfected FLAG epitope tagged HSF1 constructs. 293T cells were cotransfected with the indicated HSF1 construct with or without RSV-Raf-BXB (Bruder et al. 1992). Cells were serum-deprived overnight, ${ }^{32} \mathrm{P}_{\mathrm{i}}$-labeled for $1 \mathrm{hr}$ at $37^{\circ} \mathrm{C}(-\mathrm{HS})$ or $43^{\circ} \mathrm{C}(+\mathrm{HS})$, and cell extracts were immunoprecipitated using anti-FLAG M2 agarose. Proteins were quantified by PhosphorImager analysis. $(B)$ Expression levels of FLAG epitope-tagged HSFl constructs in parallel sets of transfected and serum-deprived 293T cells as shown in Fig. 3A obtained by Western blot analysis using M2 antibody. (C) 2-D tryptic phosphopeptide map of endogenous HSF1 immunoprecipitated from Hela cells labeled with ${ }^{32} \mathrm{P}_{\mathrm{i}}$ for $\mathrm{l}$ hr. The major spot, indicated with a bracket, comigrates with the bracketed spot in Fig. 3. (D) 2-D tryptic phosphopeptide map of FLAG epitope-tagged HSF1 wild-type and S303,307A mutant with or without Raf BXB coexpression. Immunoprecipitated HSF1 constructs from serum-deprived, ${ }^{32} \mathrm{P}_{\mathrm{i}}$-labeled $293 \mathrm{~T}$ cells were resolved by SDS-PAGE (autoradiography is shown at top) and subjected to phosphopeptide analysis. Phosphopeptide maps of HSF1 wild-type (1,2) and HSF1 S303,307 A $(3,4)$ are shown without $(1,3)$ or with $(2,4)$ coexpression of constitutively active Raf. The major phosphopeptide in wild-type HSF1 that is absent in the S303,307A mutant is indicated with a bracket.

Two specific charged residues in the vicinity of serine 303 and 307 are critical for regulatory domain function

The evidence presented above implies that phosphorylation of serines 303 and 307 plays an important role in defining the activity of the regulatory domain of HSF1. To determine whether this region of HSF1 is particularly important for function, we mutated surrounding amino acids and examined their phenotype in GAL4 fusions by cotransfection into HeLa cells. Alanine scanning of charged residues betweeen amino acids 296 and 311 revealed that lysine 298 (Newton et al. 1996) and glutamic acid 300 are critical for repression of transcriptional activation at control temperature and heat inducibility (Fig. 5A, lanes 7,8,11,12). Mutation of four other charged residues in the region to alanine had no effect on either repression or heat induction. Mutation of valine 297 to alanine gave partial derepression at control temperature. Gel shift analysis showed that the mutations had little effect on the expression level or DNA-binding ability of the fusion proteins (Fig. 5B). Taken together, these specific charged residues, along with the phosphorylated serine residues define a region that appears to be critical for regulatory domain function.

It is possible that the derepressed phenotype caused by 
A
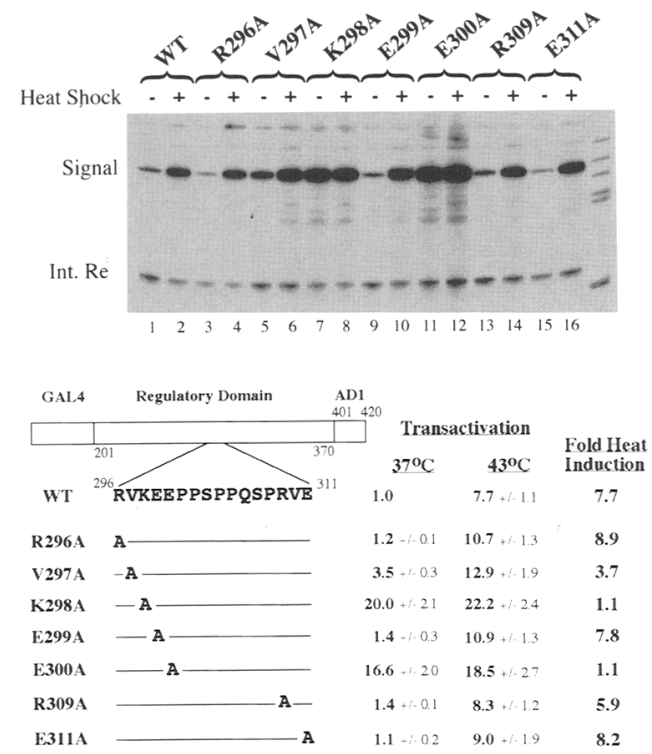

B

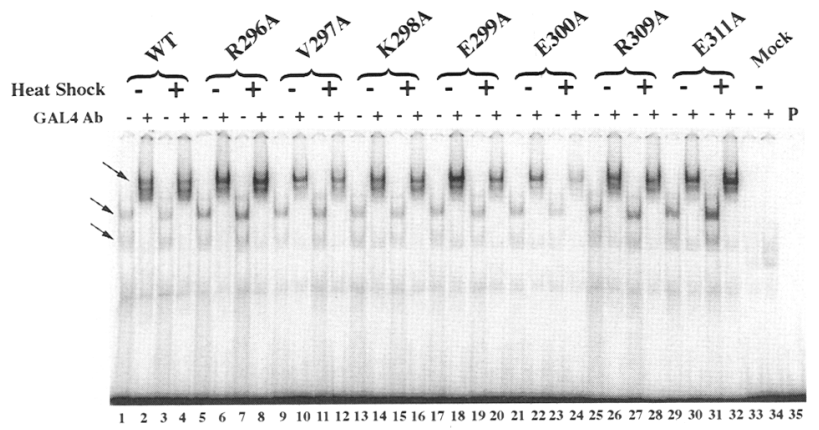

Figure 5. Two specific charged residues in the vicinity of serines 303 and 307 are critical for regulatory domain function. (A) Effects of point mutations of charged residues within the regulatory domain on transcriptional activity of GAL4-HSF1 fusion proteins as measured by $\mathrm{S} 1$ analysis. Heat shock and quantification are as in Fig. $1 \mathrm{~A}$. $(B)$ Gel shift analysis of the expression of mutant GAL4 fusion proteins relative to wild-type expression. Extracts were prepared from cells transfected in parallel with those for $A$. The GAL4 species (indicated by arrows) were supershifted in the indicated lanes with GAL4 antisera.

mutating lysine 298 to alanine and glutamic acid 300 to alanine is attributable to an effect of these mutations on phosphorylation of serine 303 and 307 . To test this hypothesis we combined an R296A, K298A mutation, which gave a derepressed phenotype, with the all serine to glutamic acid mutation, which gave a wild-type phenotype. The R296A, K298A mutation was dominant over the serine to glutamic acid mutation, as the combined mutant gave a completely derepressed phenotype, implying that this mutation functions independently of the serines (data not shown). In addition, the regulatory domain with the K298A mutation had the same level of phosphate incorporation as the wild-type regulatory domain as determined by in vivo ${ }^{32} \mathrm{P}_{\mathrm{i}}$ labeling experiments (data not shown).
Function of the regulatory domain in HSF1 at control temperature

The above data demonstrate that amino acids K298, E300, and proline directed serines are important for the activity of the regulatory domain in GAL4 fusion proteins. To verify that these mutations also affect activity in more natural settings, we introduced these mutations into either wild-type HSFl or into a variant of HSFl that contains the LexA DNA-binding domain. We took advantage of the observation that a portion of transfected HSFl is activated to bind to DNA at control temperature (Rabindran et al. 1993) to analyze the effects of these mutants on transcriptional activation (note that these mutations appear to have no phenotype at $43^{\circ} \mathrm{C}$, Figs. 1 and 5). The LexA fusion proteins contain amino acids 84-529 of HSFl, which includes the HSFl trimerization domain, and have been shown previously to be regulated in a manner similar to intact HSF1 at the levels of both DNA binding and transcriptional activation (Zuo et al. 1994; data not shown). HeLa cells were co-transfected with LexA-HSF1 expression plasmids containing the different mutations in the regulatory domain and a LexAdriven CAT reporter. A growth hormone expression vector was used as internal control for transfection efficiency. CAT assays were performed to monitor the LexA-HSF activity within the cells at $37^{\circ} \mathrm{C}$. The K298A mutation in this context led to a 18.5 -fold derepression compared with wild type, whereas the mutation of proline-directed serine to alanine led to a 6.3-fold derepression (Fig. 6A). As expected, mutation of these serines to glutamic acid had very little effect.

To determine whether mutations in these residues affect function of intact HSF1, we introduced wild-type and mutant HSF1 plasmids along with an HSE-driven CAT reporter into HeLa cells. Transfection of wild-type HSF 1 causes only a marginal increase in CAT activity compared with mock-transfected cells (Fig. 6B). Expression of HSFl containing the K298A mutation led to 11fold higher CAT activity, and mutation of proline-directed serine to alanine showed a 3.6-fold stimulation. These proteins were expressed at similar levels, as shown by Western analysis (Fig. 6C). We conclude that mutations in the regulatory domain have similar effects in full-length HSF1, LexA fusion proteins that contain all amino acids carboxy-terminal of 84 , and in GAL4 fusion proteins that contain smaller regions of HSFl.

\section{Discussion}

The results presented here suggest a mechanism for repression of HSF 1 activity at control temperatures by phosphorylation of proline-directed serine motifs. Although it is not yet clear which of several kinases with this specificity might phosphorylate HSF1, our results establish the Raf/ERK pathway as a candidate to phosphorylate this domain in vivo. The mutational analyses indicate that the consequence of this phosphorylation is an inhibition of the ability of HSF1 to activate transcription. These results provide a mechanism by which HSF 1 
A

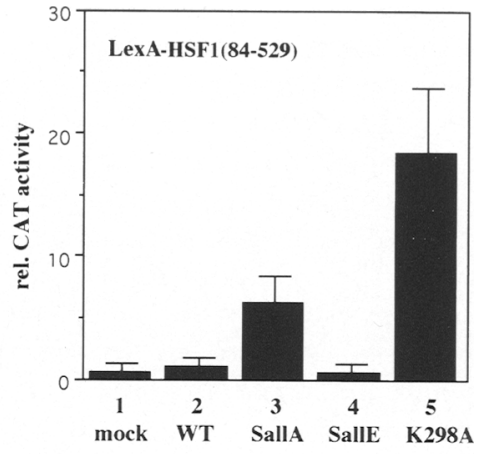

B

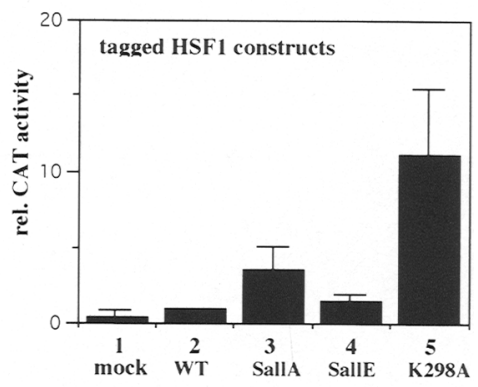

C

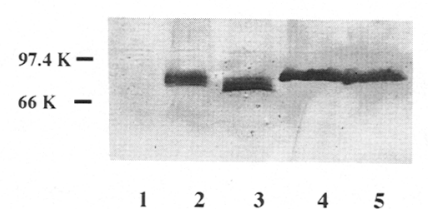

Figure 6. The regulatory domain represses the transactivation potential of HSFl at control temperature. (A) Transcriptional activity of LEXA-HSF1 constructs. HeLa cells were transfected with an LEXA-CAT reporter, the internal reference plasmid pXGH5 and pCMV5 (lane 1) or pCMV LEXA(1-87) HSF1(84 529) constructs harboring the wild-type regulatory domain (lane 2) or the indicated point mutations (lanes 3-5). Relative CAT activities (average from three different experiments with standard deviation) determined 36 hr post-transfection and corrected for transfection efficencies are shown. $(B)$ Transcriptional activity of full-length HSF1 constructs. HeLa cells were transfected with pCMV5 (lane 1), pCMV-HSF1 flag (lane 2), or the appropriate HSFl constructs harboring the indicated point mutations within the regulatory domain (lanes 3-5) along with an HSE-CAT reporter and pXGH5 as internal reference. Relative CAT activities were determined as $A .(C)$ Western blot showing expression level of constucts from $B$, using anti-FLAG M2 antibody.

activity might be modulated by signaling pathways that respond to growth conditions.

Positive and negative regulation by MAP kinase related pathways

Phosphorylation by MAP kinase-related pathways has been shown to modulate transcriptional activator func- tion, and can affect stability, nuclear localization, DNAbinding, and transactivation (for review, see Hunter and Karin 1992; Hill and Treisman 1995). In HSF1, phosphorylation occurs in the regulatory domain, and is necessary for full repression of the transcriptional activation domains. In contrast, stimulation of the Raf/ERK pathway results in up-regulation of activator function in most of the systems studied. In mammals, phosphorylation of the ternary complex factors Elk-1 and SAP-1 increases the transcriptional activation potential of these proteins (Marais et al. 1993; Zinck et al. 1993), as does phosphorylation of Ets-1 and Ets-2 (Yang et al. 1996). In Drosophila eye development two Ets-related proteins, yan and pointed $^{\mathrm{P} 2}$, are both downstream targets of ERKA, and phosphorylation of pointed increases its transactivation potential, whereas phosphorylation of the repressor yan inhibits its ability to repress (O'Neill et al. 1994). Increased repression following phosphorylation by ERK kinases has been proposed for c-Fos in mammals and Bicoid in Drosophila, although the mechanism by which phosphorylation functions in these cases has not been established (Ofir et al. 1990; Chen et al. 1993; Ronchi et al. 1993; Okazaki and Sagata 1995). Thus, two separate mechanisms have evolved that allow similar or identical kinase pathways to regulate activators by either increasing function (e.g., Elk-1) or decreasing function (e.g., HSF1).

There are several proline-directed serine/threonine kinases in the cell (Cano and Mahadevan 1995). In addition to ERK, p38 is capable of phosphorylating the regulatory domain (Fig. 2), and there are numerous other kinases, including CDKs, that might also have this activity. Even more kinases with similar substrate specificity are being discovered. This raises the possibility that several different kinases might modulate HSF1 activity via the mechanisms that we propose here. Further characterization of these different kinase pathways and their effects on HSFl phosphorylation will be required to establish how broad this mechanism of regulation of HSF1 activity is.

\section{Implications for regulation of HSF1 activity in vivo}

HSF1 is normally found in a non-DNA-binding monomeric state that is converted to a DNA-binding trimer in response to a wide variety of cellular stresses, pharmacological treatments, and physiological conditions (Morimoto et al. 1992). Under mild stress conditions, inhibition of the transactivation potential of HSF1 by phosphorylation might provide an additional level of regulation to prevent a high level of heat shock gene induction when it is not needed or is detrimental for cell growth. HSPs fulfill protective functions under cellular stress conditions mainly because of their ability to act as molecular chaperones, but under normal conditions artificial overexpression can lead to an inhibition of cell proliferation (Feder et al. 1992; Knauf et al. 1992). Consistent with the experiments reported here, two recent studies have shown an inhibitory effect of the Raf/ERK pathway on heat shock gene transcription. Overexpression of a dominant inhibitory mutant of ERK1 increases 
hsp70 reporter gene activity in NIH-3T3 cells after a short heat treatment (Mivechi and Giaccia 1995), whereas in Ha-ras-transformed rat fibroblasts the induction of hsp68 transcription is decreased (Engelberg et al. 1994). The ability of HSF1 to integrate signaling pathways via phosphorylation of the regulatory domain might be one mechanism to modulate the cellular stress response in response to different growth conditions. A direct test of this hypothesis will require the development of systems that allow characterization of HSF1 function under more physiological induction conditions, and that allow a direct determination of which kinase phosphorylates the regulatory domain under those conditions.

Phosphorylation does not appear to affect regulatory domain function under the severe stress of heating to $43^{\circ} \mathrm{C}$. Mutation of the proline-directed serine motifs in the regulatory domain has no phenotype under heat shock conditions; both wild-type and mutant proteins are maximally induced (Fig. 1). Dephosphorylation of the regulatory domain is not necessary for heat shock-induced transcription, as the phosphorylation level of the GAL4-HSF1 constructs is not affected by heat treatment and mutants in which the serines have been changed to glutamic acid are still fully heat shock-inducible (Fig. 1). This is consistent with a role for the regulatory domain in receiving growth signals: Under conditions of severe stress, HSF might be expected to be maximally activated regardless of cellular growth conditions because proper induction of heat shock gene expression is necessary to ensure cell survival. Thus, modulation of the regulatory domain of HSF1 by phosphorylation might be an important mechanism that provides the appropriate level of HSFl activity under various normal growth conditions, but is overridden upon severe stress.

\section{A model for regulatory domain function}

The regulatory domain of HSFl can function in the absence of other portions of HSFl. When this domain is placed in a protein with the GAL4 DNA-binding domain and a portion of the VP16 activation domain, it represses activation domain function at normal growth temperatures and confers heat inducibility (Newton et al. 1996). We have mapped a critical region of this domain: mutation of charged amino acids at 298 or 300 eliminates function of the regulatory domain; mutation of serines 303 and 307 to glutamic acid, which mimics a phosphorylated state, results in full function of the regulatory domain, whereas mutation of serines 303 and 307 to alanine inhibits the ability of the regulatory domain to repress transcription. Thus, phosphorylation of serines 303 and 307 would add two more charged side chains to an important region of the regulatory domain that contains other key charged amino acids. This region might form a charged interface with a separate protein that either shields the transcriptional activation domains or represses transcription directly. Alternatively, the regulatory domain might shield transcriptional activation domain function directly via specific contacts. Although we cannot rule out this latter possibility, several lines of evidence suggest the contrary. None of the amino acids in activation domain 1 , when mutated, had an effect on heat regulation (Newton et al. 1996). The regulatory domain can also repress a heterologous activation domain (Newton et al. 1996). In addition, no interaction was detected between the regulatory domain and the activation domains when tested in the two-hybrid system (M. Green, unpubl.). Therefore, to understand the mechanism by which this region of HSFl functions, it will be important to identify any proteins that interact directly with this charged region of the regulatory domain.

\section{Materials and methods}

\section{Plasmid constructions}

Point mutagenesis Point mutations were made by Kunkel mutagenesis as described previously (Newton et al. 1996), confirmed by sequencing and then subcloned back into the GAL4 RD-AD1 expression vector (Newton et al. 1996).

Expression vectors Mutations were introduced into the fulllength HSF 1 coding region by subcloning the EcoRI fragment of HSF1 cDNA (Rabindran et al. 1991) into pUC18 and replacement of the NgoMI fragment with the appropriate fragments of GAL4-RD-ADl variants. The EcoRI fragments coding for wildtype and mutant HSFs were subcloned into the mammalian expression vector pCMV5. The carboxy-terminal FLAG epitope was added using the polymerase chain reaction (PCR) with a forward primer containing the PstI site of HSFl and a reverse primer incorporating the appropriate FLAG sequence, a stop codon, and a BgIII site. PCR products were subcloned into the different pCMV HSF1 plasmids.

The LexA $(1-87)$ HSF $1(84-529)$ vector was constructed by subcloning a blunt-ended TaqI-EcoRI fragment of HSFl into EcoRIdigested, blunt-ended pSH-2-1 (Hanes and Brent 1989). The HindIII-BglII fragment of this plasmid was subcloned into pCMV5 and the RD mutations were introduced using the SphI$B g$ III fragments of the different pCMV HSF1 FLAG contructs as described above. The GST expression vectors were constructed by amplifying (PCR) the 170 amino acid wild-type RD sequence with primers containing BamHI (forward) and EcoRI (reverse) sites and subcloning into BamHI/EcoRI-digested pGEX-2TK (Pharmacia). The RD mutations were introduced subsequently by subcloning of the appropriate NgoMI fragments of the different GAL4-RD-AD1 constructs.

Reporter plasmids The CAT reporter constructs used here were G540CAT (Taylor 1991), HSECAT (Greene et al. 1987), and $\mathrm{X}_{4} \mathrm{G}_{2} \mathrm{CAT}$ (Bunker and Kingston 1994), which contain five GAL4 DNA-binding sites, two synthetic HSE sites, or four LEXA plus two GAL4-binding sites, respectively, at -40 of the hsp70 basal promoter driving the expression of the CAT gene. The internal reference plasmid pIR 17-84 contains hsp 70 promoter sequences to -84 (thus deleting the HSEs) with a deletion in the $5^{\prime}$ untranslated region driving the expression of the CAT gene (Kingston et al. 1986). This produces an S1 reference signal that is 130 nucleotides compared with 230 nucleotides for the reporter. 
Transient transfections and CAT assays

$\mathrm{HeLa}$ and $293 \mathrm{~T}$ cells were grown in DMEM $+10 \%$ calf serum at $37^{\circ} \mathrm{C}$ in $5 \% \mathrm{CO}_{2}$. Plates at $\sim 90 \%$ confluency were split $1: 10$ the day before transfection into $10-\mathrm{cm}$ dishes. Transfections were done by the $\mathrm{CaPO}_{4}$ method (Ausubel et al. 1989) and contained $15 \mu \mathrm{g}$ of total DNA. For Hela cells, $5 \mu \mathrm{g}$ expression plasmid, 5 $\mu \mathrm{g}$ G540CAT reporter plasmid, and $5 \mu \mathrm{g}$ pIR17-84 (reference for $\mathrm{S} 1$ assay) or $1 \mu \mathrm{g}$ pXGH5 (reference plasmid for CAT assay) and $\mathrm{pSK}+$ as carrier DNA were used. Chloroquine was added to the media at a final concentration of $100 \mu \mathrm{M}$ immediately prior to addition of precipitate. Cells were washed with PBS and placed into fresh medium $4 \mathrm{hr}$ later, and heat shock was induced $\sim 24$ hr posttransfection $\left(43^{\circ} \mathrm{C}\right.$ for $\left.4 \mathrm{hr}\right)$. Transfectants were harvested either immediately for $\mathrm{S} 1$ analysis or $12 \mathrm{hr}$ later for CAT assay. Cell extracts and phase-extraction CAT assays were performed as described previously (Ausubel et al. 1989). Transfection efficiency was measured using a human growth hormone-based radioimmunoassay (Nichols Institute).

$293 \mathrm{~T}$ cells were transfected for $3 \mathrm{hr}$ without chloroquinetreatment using various expression plasmids $(0.5 \mu \mathrm{g}$ if not otherwise indicated) and pSK + as carrier DNA. If indicated, cells were serum-deprived $(0.1 \%$ calf serum $) 24 \mathrm{hr}$ posttransfection for $\sim 16 \mathrm{hr}$, stimulated with phorbol-12-myristate-13-acetate (PMA, ICN Biochemicals) or anisomycin, and harvested immediately.

\section{RNA harvest and S1 analysis}

Total cellular RNA was isolated from transfected cells using RNeasy prep columns from Qiagen according to manufacturer's instructions. Single-stranded 5' end-labeled Sl probe was prepared as described previously (Kingston et al. 1986) and contains sequences from +229 to -133 of the hsp70-CAT fusion reporter construct. Total cellular RNA $(20 \mu \mathrm{g})$ was mixed with S1 probe $\left(5 \times 10^{4} \mathrm{dpm}\right)$, and hybridization, S1 nuclease digestion, and analysis on $8 \%$ denaturing polyacrylamide gels were done by standard procedures (Ausubel et al. 1989). Gels were quantitated using a Molecular Dynamics PhosphorImager.

\section{Electrophoretic mobility shift assay}

Transfected HeLa cells were washed with ice-cold PBS, duplicate plates were pooled and nuclear extracts were prepared as described previously (Lee et al. 1988). Total protein concentrations were determined by Bradford assay (Biorad). Protein $(2 \mu \mathrm{g})$ was used in a total volume of $10 \mu \mathrm{L}$ buffer D $(20 \mathrm{mM}$ HEPES at $\mathrm{pH} 7.9,20 \%$ glycerol, $0.1 \mathrm{M} \mathrm{KCl}, 0.2 \mathrm{~mm}$ EDTA, $0.5 \mathrm{~mm}$ PMSF, and $0.5 \mathrm{~mm}$ DTT) and $11 \mu \mathrm{l}$ of a salt mix was added $(20 \mathrm{~mm}$ HEPES at $\mathrm{pH} 7.5,16.67 \mathrm{mM} \mathrm{KCl}, 8.83 \mathrm{~mm} \mathrm{MgCl} 2,16.67 \mu \mathrm{M}$ $\mathrm{ZnCl}_{2}$, and $6.63 \mathrm{~mm}$ spermidine). GAL4 antibody (RK5C1, Santa Cruz Biotechnology Inc.) $(0.2 \mu \mathrm{g})$ was added and the mixture was incubated on ice for $30 \mathrm{~min}$. Poly[d(I-C)] (Pharmacia) (5 $\mu \mathrm{g}$ ) and $2.5 \mathrm{ng}$ double-stranded radiolabeled probe containing a single GAL4 site (5'-CGGAGTACTGTCCTCCG-3') was added, the mixture was incubated at $30^{\circ} \mathrm{C}$ for $15 \mathrm{~min}$, and resolved on a native $4.5 \%$ acrylamide gel in $0.5 \times \mathrm{TBE}$.

\section{Protein purification and kinase assays}

GST fusion protein expression vectors were transformed into BL21 DE3 strain of Escherichia coli. Protein induction and purification were as described (Smith and Johnson 1988). The amount of protein was estimated by the Bio-Rad protein assay.

For immunopurification of ERK1, SAPK or p38, cells were washed with ice-cold phosphate-buffered saline and lysed in lysis buffer [20 mM HEPES at $\mathrm{pH} 7.4,2 \mathrm{~mm}$ EGTA, $50 \mathrm{~mm}$ $\beta$-glycerophosphate, $1 \mathrm{mM}$ DTT, $1 \mathrm{~mm} \mathrm{Na} \mathrm{VO}_{4}, 1 \%$ Triton $\mathrm{X}-100,10 \%$ glycerol, $2 \mu \mathrm{M}$ leupeptin, $400 \mu \mathrm{M}$ phenylmethylsulfonyl flouride (PMSF), and 10 kallekrein-inhibiting units Trasylol per $\mathrm{ml}$. Extracts were cleared by centrifugation and preincubation with protein G-Sepharose (Pharmacia). Kinases were precipitated using the anti-HA mAb 12CA5 (Boehringer Mannheim) or a rabbit antiserum against SAPK (Kyriakis et al. 1994) or p38 (Rouse et al. 1994) bound to protein G-Sepharose. The immunoprecipitates were washed twice with $\mathrm{LiCl}$ buffer $1500 \mathrm{~mm} \mathrm{LiCl}, 100 \mathrm{~mm}$ Tris at $\mathrm{pH} 7.6,1 \mathrm{~mm}$ DTT, and $0.1 \%$ Triton X-100) and three times with kinase assay buffer $(20 \mathrm{~mm}$ MOPS at $\mathrm{pH} 7.2,2 \mathrm{~mm}$ EGTA, $10 \mathrm{~mm} \mathrm{MgCl}_{2}, 1 \mathrm{~mm}$ DTT, and $0.1 \%$ Triton $\mathrm{X}-100$ ). Kinase reactions were initiated by addition of $2 \mu \mathrm{g}$ of substrate proteins [GST-RD, GST-c Jun(1-135), myelin basic protein (MBP) (Sigma)] and $100 \mu \mathrm{M}\left[\gamma^{-}{ }^{32} \mathrm{P}\right] \mathrm{ATP}$ (5000 $\mathrm{cpm} / \mathrm{pmole}$ ) in a final volume of $60 \mu \mathrm{l}$ of kinase buffer. The reactions were stopped after $20 \mathrm{~min}$ at $30^{\circ} \mathrm{C}$ by addition of SDS sample buffer and analyzed by SDS-PAGE and autoradiography. Quantitation was performed using a Molecular Dynamics PhosphorImager.

\section{Western blotting}

Similar amounts of whole-cell extracts were resolved by SDSPAGE on $10 \%$ gels, blotted onto nitrocellulose (Schleicher \& Schuell), and subjected to Western blotting analysis using M2 anti-Flag mAb (IBI Kodak) or rabbit antiserum against GAL4 (kindly provided by M. Ptashne, Harvard University, Cambridge, MA). The antibody-antigen complexes were visualized by the enhanced chemiluminescence detection system (Amersham).

\section{In vivo labeling and immunoprecipitation}

Transfected $293 \mathrm{~T}$ cells were washed in prewarmed $\left(37^{\circ} \mathrm{C}\right)$ phosphate-free minimal essential medium (Gibco BRL) and labeled in $1 \mathrm{ml}$ of medium supplemented with $2 \%$ dialyzed fetal bovine serum (omitted in serum-deprived samples) and $0.5 \mathrm{mCi}$ of ${ }^{32} \mathrm{P}_{\mathrm{i}}$ (DuPont/New England Nuclear) for $60 \mathrm{~min}$ at 37 or $43^{\circ} \mathrm{C}$. Cells were washed with ice-cold phosphate-buffered saline, and lysed in radioimmune precipitation buffer [RIPA: $10 \mathrm{~mm}$ Tris at $\mathrm{pH}$ 8.0, $0.1 \mathrm{M} \mathrm{NaCl}, 1 \mathrm{~mm}$ EDTA, $10 \%$ glycerin, $1 \%$ Nonidet P-40, $0.5 \%$ sodium deoxycholate, and $0.1 \%$ sodium dodecyl sulfate [SDS)] supplemented with $50 \mathrm{~mm} \beta$-glycerophosphate, $1 \mathrm{~mm}$ $\mathrm{Na}_{3} \mathrm{VO}_{4}, 40 \mathrm{mM} \mathrm{NaF}, 2 \mu \mathrm{M}$ leupeptin, $400 \mu \mathrm{M}$ PMSF, and 10 kallekrein-inhibiting units of Trasylol per $\mathrm{ml}$. The lysates were cleared by centrifugation and equal counts from all samples were incubated with a rabbit antiserum against HSF1 (kindly provided by R. Morimoto, Northeastern University, Boston, MA) or GAL4 (kindly provided by M. Ptashne). Two hours later protein A-Sepharose (Pharmacia) was added and incubation was continued for $1 \mathrm{hr}$. Flag-tagged proteins were immunoprecipitated using M2 affinity gel (IBI Kodak) and modified RIPA buffer (10 mM Tris at $\mathrm{pH} 7.4,0.15 \mathrm{M} \mathrm{NaCl}, 1 \mathrm{~mm}$ EDTA, $10 \%$ glycerin, $0.1 \%$ Nonidet $\mathrm{P}-40$, and $1 \%$ Triton X-100). Immune complexes were washed $4 \times$ with the appropriate RIPA buffer, which was supplemented with $1 \mathrm{M} \mathrm{NaCl}$ in the first washing step. Pellets were boiled in SDS sample buffer and analyzed by SDS-PAGE (10\% acrylamide) and autoradiography.

\section{Tryptic phosphopeptide analysis}

In vitro phosphorylation of GST-RD fusion proteins was performed using a purified ERK1/2 preparation (Mukhopadhyay et al. 1992). GST proteins $(5 \mu \mathrm{g}$ ) were phosphorylated in kinase 
assay buffer at $30^{\circ} \mathrm{C}$ with $100 \mu \mathrm{M}\left[\gamma^{-32} \mathrm{P}\right] \mathrm{ATP}(20,000 \mathrm{cpm} /$ pmole). Reactions were stopped $60 \mathrm{~min}$ later by adding SDS sample buffer.

For phosphopeptide analysis of in vivo labeled HSFl, Hela cells were ${ }^{32} \mathrm{P}_{\mathrm{i}}$-labeled using $2 \mathrm{mCi} / \mathrm{ml}$ and $\mathrm{HSFl}$ was immunoprecipitated. Proteins were separated by SDS-PAGE and blotted onto nitrocellulose. The appropriate bands were cut and proteins were digested with TPCK-treated trypsin (Worthington) as described (Boyle et al. 1991). Labeled peptides were lyophilized, spotted onto microcellulose glass-backed TLC plates (Merk) and analyzed by $2-\mathrm{D}$ peptide mapping. Electrophoresis was carried out on LKB Multiphor II (Pharmacia) at $1.0 \mathrm{kV}$ for 25 min using $\mathrm{pH} 1.9$ buffer $[25 \mathrm{ml}$ formic acid $(88 \%), 78 \mathrm{ml}$ glacial acetic acid, and $897 \mathrm{ml} \mathrm{H}_{2} \mathrm{O}$ ]. Ascending chromatography was performed in $n$-butyl alcohol/pyridine/glacial acetic acid/water (15:10:3:12) for $7-9 \mathrm{hr}$. Plates were exposed at $-80^{\circ} \mathrm{C}$ with an intensifying screen for 2-3 days.

\section{Acknowledgments}

We wish to thank M. Ptashne, R. Morimoto, and A. Nebreda for providing the GAL4, HSF, and p38 antibodies, respectively; J.L. Volker for useful discussions throughout and for technical assistance in tryptic mapping; U. Hansen for use of the electrophoresis apparatus; and J. Blenis, T. Grammer, G. Schnitzler, and R. Treisman for useful discussions.

U.K. is supported by a postdoctoral fellowship from Boehringer Ingelheim and E.M.N. is supported by a graduate studentship from the Medical Research Council of Canada. This research was supported by grants from the National Institutes of Health (GM43901) and from Hoechst AG.

The publication costs of this article were defrayed in part by payment of page charges. This article must therefore be hereby marked "advertisement" in accordance with 18 USC section 1734 solely to indicate this fact.

\section{References}

Ausubel, F.M., R. Brent, R.E. Kingston, D.D. Moore, J.G. Seidman, J.A. Smith, and K. Struhl, eds. 1989. Current protocols in molecular biology. Wiley and Sons, New York, NY.

Boyle, W.J., P. Van Der Geer, and T. Hunter. 1991. Phosphopeptide mapping and phosphoamino acid analysis by two-dimensional separation on thin-layer cellulose plates. Methods Enzymol. 201: 110-149.

Bruder, J.T., G. Heidecker, and U. Rapp. 1992. Serum-, TPA-, and Ras-induced expression from Ap-1/Ets-driven promoters requires Raf-1 kinase. Genes \& Dev. 6: 545-556.

Bunker, C.A. and R.E. Kingston. 1994. Transcriptional repression by Drosophila and mammalian polycomb group proteins in transfected mammalian cells. Mol. Cell. Biol. 14: 1721-1732.

Cano, E. and L.C. Mahadevan. 1995. Parallel signal processing among mammalian MAPKs. Trends Biochem. Sci. 20: 117122.

Chen, Y., N.A. Barlev, O. Westergaard, and B.K. Jakobsen. 1993. Identification of the $\mathrm{C}$-terminal activator domain in yeast heat shock factor: Independent control of transient and sustained transcriptional activity. EMBO /. 12: 5007-5018.

Cotto, J.J., M. Kline, and R.I. Morimoto. 1996. Activation of heat shock factor 1 DNA binding precedes stress-induced serine phosphorylation. J. Biol. Chem. 271: 3355-3358.

Derijard, B., M. Hibi, I.-H. Wu, T. Barrett. B. Su, T. Deng, M. Karin, and R.J. Davis. 1994. JNK-1: A protein kinase stimu- lated by UV light and Ha-Ras that binds and phosphorylates the c-Jun activation domain. Cell 76: 1025-1037.

Derijard, B., J. Raingeaud, T. Barret, I.-H. Wu, J. Han, R.J. Ulevitch, and R.J. Davis. 1995. Independent human MAP-kinase signal transduction pathways defined by MEK and MKK isoforms. Science 267: 682-685.

Engelberg, D., E. Zandi, C.S. Parker, and M. Karin. 1994. The yeast and mammalian Ras pathways control transcription of heat shock genes independently of heat shock transcription factor. Mol. Cell. Biol. 14: 4929-4937.

Feder, J.H., J.M. Rossi, J. Solomon, and S. Lindquist. 1992. The consequences of expressing hsp70 in Drosophila cells at normal temperatures. Genes \& Dev. 6: 1402-1413.

Green, M., T.J. Schuetz, E.K. Sullivan, and R.E. Kingston. 1995. A heat shock-responsive domain of human HSFl that regulates transcription activation domain function. Mol. Cell. Biol. 15: 3354-3362.

Greene, J.M., Z. Larin, I.C.A. Taylor, H. Prentice, K.A. Gwinn, and R.E. Kingston. 1987. Multiple basal elements of a human hsp70 promoter function differently in human and rodent cell lines. Mol. Cell. Biol. 7: 3646-3655.

Han, J., J.-D. Lee, L. Bibbs, and R.J. Ulevitch. 1994. A MAP kinase targeted by endotoxin and hyperosmolarity in mammalian cells. Science 265: 808-810.

Hanes, S. and R. Brent. 1989. DNA specificity of the bicoid activator protein is determined by homodomain recognition helix residue 9. Cell 57: 1275-1283.

Hill, C.S. and R. Treisman. 1995. Transcriptional regulation by extracellular signals: Mechanisms and specificity. Cell 80: $199-211$

Hoj, A. and B.K. Jakobsen. 1994. A short element required for turning off heat shock transcription factor: Evidence that phosphorylation enhances deactivation. EMBO J. 13: 26172624.

Hunter, T. and M. Karin. 1992. The regulation of transcription by phosphorylation. Cell 70: 375-387.

Karin, M. and T. Hunter. 1995. Transcriptional control by protein phosphorylation: Signal transmission from the cell surface to the nucleus. Curr. Biol. 5: 747-757.

Kingston, R.E., R.I. Cowie, R.I. Morimoto, and K.A. Gwinn. 1986. Binding of polyomavirus large $T$ antigen to the human hsp70 promoter is not required for transactivation. Mol. Cell. Biol. 6: 3180-3190.

Knauf, U., H. Bielka, and M. Gaestel. 1992. Over-expression of the small heat-shock protein, hsp25, inhibits growth of Ehrlich ascites tumor cells. FEBS Lett. 309: 297-302.

Kyriakis, J.M., P. Banerjee, E. Nikolakaki, T. Dai, E.A. Rubie, M.F. Ahmad, J. Avruch, and J.R. Woodgett. 1994. The stressactivated protein kinase subfamily of c-Jun kinases. Nature 369: $156-160$.

Lange-Carter, C.A., C.M. Pleiman, A.M. Gardner, K.J. Blumer, and G.L. Johnson. 1993. A divergence in the MAP kinase regulatory network defined by MEK kinase and Raf. Science 260: 315-319.

Larson, J.S, T.J. Schuetz, and R.E. Kingston. 1995. In vitro activation of purified human heat shock factor by heat. Biochemistry 34: 1902-1911.

Lee, K.A.W., A. Bindereif, and M.R. Green. 1988. A small-scale procedure for preparation of nuclear extracts that support efficient transcription and pre-mRNA splicing. Gene Anal. Tech. 5: 22-31.

Lin, A., A. Minden, H. Martinetto, F.X. Claret, C. Lange-Carter, F. Mercurio, G.L. Johnson, and M. Karin. 1995. Identification of a dual specificity kinase that activates the Jun kinases and p38-Mpk2. Science 268: 286-290.

Lis, J. and C. Wu. 1993. Protein traffic on the heat shock pro- 
moter: Parking, stalling, and trucking along. Cell 74: 1-4.

Marais, R., J. Wynne, and R. Treisman. 1993. The SRF accessory protein Elk-1 contains a growth factor-regulated transcriptional activation domain. Cell 73: 381-393.

Minden, A., A. Lin, M. McMahon, C. Lange-Carter, B. Derijard, R.J. Davis, G.L. Johnson, and M. Karin. 1994. Differential activation of ERK and JNK mitogen-activated protein kinases by Raf-1 and MEKK. Science 266: 1719-1722.

Mivechi, N.F. and A.J. Giaccia. 1995. Mitogen-activated protein kinase acts as a negative regulator of the heat shock response in NIH3T3 cells. Cancer Res. 55: 5512-5519.

Morimoto, R.I., K.D. Sarge, and K. Abravaya. 1992. Transcriptional regulation of heat shock genes. I. Biol. Chem. 267: 21987-21990.

Mukhopadhyay, N.K., D.J. Price, J.M. Kyriakis, S. Pelech, J. Sanghera, and J. Avruch. 1992. An array of insulin-activated, proline-directed serine/threonine protein kinases phosphorylate the p70 S6 kinase. I. Biol. Chem. 267: 3325-3335.

Newton, E.M., U. Knauf, M. Green, and R.E. Kingston. 1996. The regulatory domain of human heat shock factor 1 is sufficient to sense heat stress. Mol. Cell. Biol. 16: 839-846.

Ofir, R., V.J. Dwarki, D. Rashid, and I.M. Verma. 1990. Phosphorylation of the $\mathrm{C}$ terminus of Fos protein is required for transcriptional transrepression of the c-fos promoter. Nature 348: 80-82.

Okazaki, K. and N. Sagata. 1995. The Mos/MAP kinase pathway stabilizes c-Fos by phosphorylation and augments its transforming activity in NIH 3T3 cells. EMBO J. 14: 5048-5059.

O'Neill, E.M., I. Rebay, R. Tjian, and G.M. Rubin. 1994. The activities of two Ets-related transcription factors required for drosophila eye development are modulated by the Ras/ MAPK pathway. Cell 78: 137-147.

Price, D.J., J.R. Grove, V. Calvo, J. Avruch, and B.E. Bierer. 1992. Rapamycin-induced inhibition of the 70-kilodalton S6 protein kinase. Science 257: 973-977.

Rabindran, S.K., G. Giorgi, J. Clos, and C. Wu. 1991. Molecular cloning and expression of a human heat shock factor, HSF1. Proc. Natl. Acad. Sci. 88: 6906-6910.

Rabindran, S.K., R.I. Haroun, J. Clos, J. Wisiewski, and C. Wu. 1993. Regulation of heat shock factor trimer formation: Role of a conserved leucine zipper. Science 259: 230-234.

Raingeaud, J., A.J. Whitmarsh, T. Barret, B. Derijard, and R.J. Davis. 1996. MKK3- and MKK6-regulated gene expression is mediated by the p38 mitogen-activated protein kinase signal transduction pathway. Mol. Cell. Biol. 16: 1247-1255.

Ronchi, E., J. Treisman, N. Dostatni, G. Struhl, and C. Desplan. 1993. Down-regulation of the drosophila morphogen bicoid by the torso receptor-mediated signal transduction cascade. Cell 74: 347-355.

Rouse, J., P. Cohen, S. Trigon, M. Morange, A. Alonso-Llamazares, D. Zamanillo, T. Hunt, and A.R. Nebreda. 1994. A novel kinase cascade triggered by stress and heat chock that stimulates MAPKAP kinase-2 and phosphorylation of the small heat shock proteins. Cell 78: 1027-1037.

Sanchez, I., R.T. Hughes, B.J. Mayer, K. Yee, J.R. Woodgett, J. Avruch, J.M. Kyriakis, and L.I. Zon. 1994. Role of SAPK/ ERK kinase-1 in the stress-activated pathway regulating transcription factor c-Jun. Nature 372: 794-798.

Sarge, K.D., S.P. Murphy, and R.I. Morimoto. 1993. Activation of heat shock gene transcription by heat shock factor 1 involves oligomerization, acquisition of DNA-binding activity, and nuclear localization and can occur in the absence of stress. Mol. Cell. Biol. 13: 1392-1407.

Shi, Y., P.E. Kroeger, and R.I. Morimoto. 1995. The carboxylterminal transactivation domain of heat shock factor 1 is negatively regulated and stress responsive. Mol. Cell. Biol.
15: 4309-4318.

Sistonen, L., K.D. Sarge, B. Phillips, K. Abravaya, and R.I. Morimoto. 1992. Activation of heat shock factor 2 during hemininduced differentiation of human erythroleukemia cells. Mol. Cell. Biol. 12: 4104-4111.

Smith, D.B. and K.S. Johnson. 1988. Single-step purification of polypeptides expressed in Escherichia coli as fusions with glutathione S-transferase. Gene 67: 31-40.

Sorger, P.K. 1990. Yeast heat shock factor contains separable transient and sustained response transcriptional activators. Cell 62: 793-805.

Sorger, P.K. and H.C.M. Nelson. 1989. Trimerization of a yeast transcriptional activator via a coiled-coil motif. Cell 59: $807-813$.

Taylor, I.C.A. 1991. Mechanisms of upstream transcription factor function. Ph.D. thesis, Harvard University.

Westwood, J.T. and C. Wu. 1993. Activation of Drosophila heat shock factor: Conformational change associated with a monomer-to-trimer transition. Mol. Cell. Biol. 13: 34813486.

Yan, M., T. Dai, J.C. Deak, J.M. Kyriakis, L.I. Zon, J.R. Woodgett, and D.J. Templeton. 1994. Activation of stressactivated protein kinase by MEKK1 phosphorylation of its activator SEK1. Nature 372: 798-800.

Yang, B.-S., C.A. Hauser, G. Henkel, M.S. Colman, C. Van Beveren, K.J. Stacey, D.A. Hume, R.A. Maki, and M.C. Ostrowski. 1996. Ras-mediated phosphorylation of a conserved threonine residue enhances the transactivation activities of c-Ets1 and c-Ets2. Mol. Cell. Biol. 16: 538-547.

Zinck, R., R.A. Hipskind, V. Pingoud, and A. Nordheim. 1993. c-fos transcriptional activation and repression correlate temporally with the phosphorylation status of TCF. EMBO J. 12: 2377-2387.

Zuo, J., R. Baler, G. Dahl, and R. Voellmy. 1994. Activation of the DNA-binding ability of human heat shock factor 1 may involve the transition from an intramolecular to an intermolecular triple-stranded coiled-coil structure. Mol. Cell. Biol. 14: 7557-7568.

Zuo, J., D. Rungger, and R. Voellmy. 1995. Multiple layers of regulation of human heat shock transcription factor 1. Mol. Cell. Biol. 15: 4319-4330. 


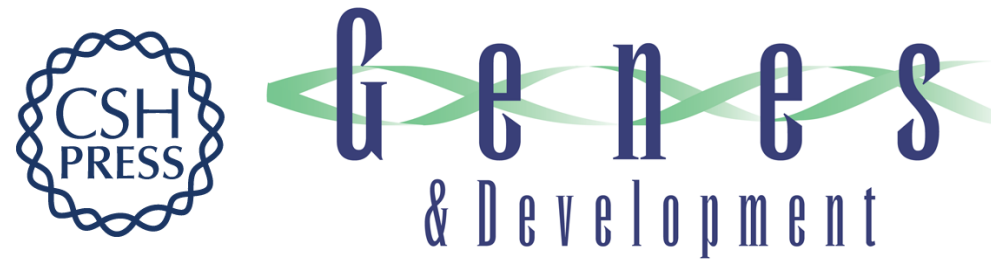

\section{Repression of human heat shock factor 1 activity at control temperature by phosphorylation.}

U Knauf, E M Newton, J Kyriakis, et al.

Genes Dev. 1996, 10:

Access the most recent version at doi:10.1101/gad.10.21.2782

References This article cites 54 articles, 28 of which can be accessed free at:

http://genesdev.cshlp.org/content/10/21/2782.full.html\#ref-list-1

License

Email Alerting

Service

Receive free email alerts when new articles cite this article - sign up in the box at the top right corner of the article or click here.

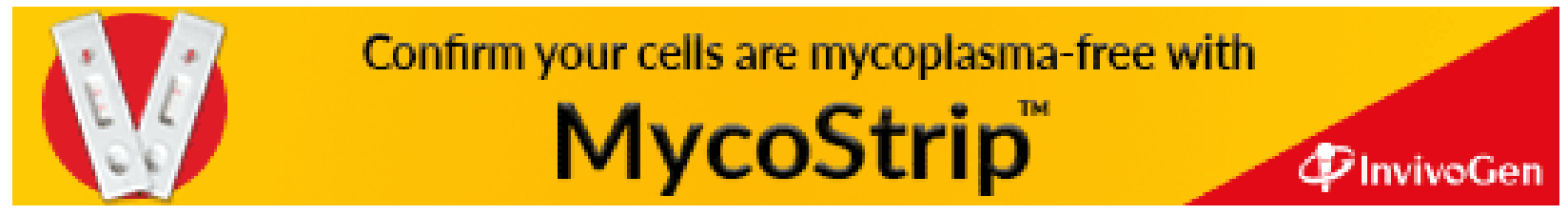

